\title{
El ateísmo hegeliano
}

\section{The Hegelian Atheism}

\author{
Jesús EZQUERRA GÓMEZ
}

Universidad de Zaragoza

Recibido: 18/05/2010

Aceptado: 16/09/2010

\section{Resumen}

El ateísmo hegeliano es un ateísmo de la muerte de Dios. Si el Dios hegeliano es lo mismo que el lógos (es decir, la racionalidad de lo real) entonces la enajenación (Entaüsserung) de la Idea lógica en la naturaleza ha de ser entendida como la muerte de Dios. Esa enajenación obedece a la dialéctica del fundamento expuesta en la lógica de la esencia: la esencia es el fundamento (Grund) abisal de la existencia (Existenz). Dicho de otro modo: la esencia funda la existencia hundiéndose, es decir, desapareciendo como tal esencia. De modo análogo la muerte de Dios es fundamento de lo real. Dios así no es sino la muerte de Dios.

Palabras clave: Hegel, ateísmo, muerte de Dios, esencia, reflexión, contradicción, fundamento, existencia, realidad.

\section{Abstract}

The Hegelian atheism is an atheism of the God's death. If the hegelian God is the same thing that the logos (that is to say, the rationality of the real) then the alienation (Entaüsserung) of the logical Idea in the Nature must be understood as the God's death. That alienation is due to the dialectics of the Ground (Grund) exposed 
in the logic of the essence: The essence is the abyssal Ground of the existence (Existenz). Said otherwise: the essence founds the existence sinking, that is to say, disappearing as such essence. Similarly the God's death is the Ground of the real. So God is not but the God's death.

Keywords: Hegel, atheism, God's death, essence, reflection, contradiction, ground, existence, reality.

\section{Un ateísmo cristiano}

Como dice George Steiner en sus conversaciones con Pierre Boutang, lo humano tiene lugar entre el viernes en que murió Cristo y el domingo en que resucitará. ${ }^{1}$ El sábado sería el "entre" sin Dios en el que habitamos los hombres, a la vez huérfanos de Dios y a la espera de Dios. Huérfanos de Dios y a la espera de Dios son, por así decir, los éxtasis de ese "entre". Orfandad y espera que nos remiten a las dos tradiciones religiosas mesiánicas: el cristianismo y el judaísmo. Ambas pueden desembocar en sendos ateísmos.

El ateísmo judío sería el de un mesianismo extremado: la espera desesperanza$d a$ de Dios. Dios nunca vendrá a redimir a los hombres, y si viene será ya demasiado tarde. Un ateísmo de este tipo es el de Franz Kafka cuando escribe:

El Mesías vendrá cuando ya no se le necesite, vendrá un día después de su venida, no vendrá el último día sino el día de después. ${ }^{2}$

El día de después del último día, es decir: nunca.

El ateísmo cristiano, por el contrario, ahistoriza la muerte de Dios: Dios ha estado siempre muerto. La muerte no es algo que acontezca a la divinidad sino su naturaleza misma. Dios es la muerte de Dios.

Nunca, siempre: ambos tipos de ateísmo sitúan a Dios en un tiempo fuera del tiempo. En el primero, el ateísmo judío, Dios es remitido a un futuro intemporal: el futuro del tiempo. En el segundo, el cristiano, Dios se encuentra relegado a un pasado no menos intemporal: el pasado del tiempo.

De esta última clase es el ateísmo hegeliano. No el del descreído sino el del cristiano consecuente. Hegel ilustra así de un modo conspicuo la tesis blochiana de que

\footnotetext{
${ }^{1}$ Boutang, P. \& Steiner, G.: Diálogos. Sobre el mito de Antígona y el sacrificio de Abraham, Barcelona, Destino, 1994, pp.106-108.

2 Das dritte Oktavheft, en Kafka, F.: Hochzeitsvorbereitungen auf dem Lande und andere Prosa aus dem Nachlass (ed. M. Brod), Frankfurt a. M., Fischer Taschenbuch Verlag, 1998, p. 67.
} 
sólo un ateo puede ser un buen cristiano, y sólo un cristiano puede ser un buen ateo. ${ }^{3}$

\section{Dios es la absoluta contradicción en sí misma}

A propósito de Spinoza, Hegel expone en sus Lecciones sobre la historia de la filosofía tres tipos de relación entre Dios y lo finito. ${ }^{4}$ El primero, que Hegel define como ateísmo, afirma que sólo lo finito es y, correlativamente, Dios no es. Lo finito está aquí -dice Hegel- tomado absolutamente (absolut genommen). Absolutamente, es decir, suelto respecto a (ab-solutus) Dios. El segundo, que podemos considerar acosmismo (es la posición que Hegel atribuye a Spinoza), afirma que sólo Dios es. Lo finito no es verdaderamente (wahrhaft) sino sólo como mero fenómeno (Phänomen) o apariencia (Schein). Tanto el ateísmo como el acosmismo expresan una relación consistente en una falta de relación: uno de los términos o relatos falta: Dios en el ateísmo, el mundo en el acosmismo. El tercer tipo de relación, que podríamos asimilar al teismo, afirma que Dios es y también las cosas finitas. Sólo contra este teísmo dualista arremete Hegel:

la razón no puede permanecer estancada con tal también, con tal indiferencia (Gleichgültigkeit). La exigencia filosófica es por lo tanto concebir la unidad de estos diferentes (Unterschiede), de tal modo que la diferencia no llegue a ser omitida, sino que brote eternamente de la substancia, y no llegue a petrificarse en el dualismo. ${ }^{5}$

La terminología utilizada aquí ("Gleichgültigkeit", "Unterschied") evoca la categoría de la Verschiedenheit (la diversidad) en la lógica de la reflexión. La diversidad es definida allí justamente como la indiferencia de la diferencia (der Gleichgültigkeit des Unterschieds). ${ }^{6}$ Dios y lo finito son, en efecto, para la concep-

\footnotetext{
3 Bloch, E.: El ateísmo en el cristianismo, Madrid: Taurus, 1983, p. 16. Sobre la relación de Hegel con el cristianismo véase Löwith, K.: "Hegels Aufhebung der christlichen Religion", en Gadamer, H.-G. (Hrsg.): Heidelberger Hegel-Tage 1962, Bonn, Bouvier Verlag Herbert Grundmann, 19842 (= HegelStudien, Beiheft 1), pp. 193-236.

${ }^{4}$ Hegel, G.W.F.: Werke, Frankfurt a. M., Suhrkamp, 1986, t. XX, p. 162 (citaré en adelante esta edición con la abreviatura: $W$ ).

5 Ibid.

6Véase: Wissenschaft der Logik. Die Lehre vom Wesen (1813) (a partir de ahora citaré esta obra con la abreviatura $W d L$ seguida del año de publicación: 1812 en el caso de la primera edición de la doctrina del ser, 1813 en el de la doctrina de la esencia, 1816 en el de la doctrina del concepto y 1832 en el de la segunda edición de la doctrina del ser): Hegel, G.W.F.: Gesammelte Werke, ed. crítica de la Rheinisch-Westfälischen Akademie der Wissenschaften en colaboración con la Deutschen Forschungsgemeinschaft, Hamburgo, Felix Meiner, 1968 y ss., t. XI, p. 267 y ss. (Citaré en adelante esta edición con la abreviatura: $G W$ ).
} 
ción teísta, diversos, es decir, indiferentemente diferentes. No se reconocen cada uno en el otro, como tal otro. La "exigencia filosófica", sin embargo, consiste en "concebir la unidad de estos diferentes" sin que su diferencia sea omitida. ¿Qué unidad es esta que no ha de omitir la diferencia en su seno?

La categoría de la diversidad, en tanto que momento abstracto y parcial de la reflexión, exige desde sí misma su superación. Diferencia (Unterschied), diversidad (Verschiedenheit) y oposición (Gegensatz) son determinaciones de la reflexión que conducen a, y desembocan en, la contradicción (Widerspruch). La contradicción es justamente esa unidad de los diferentes que los conserva como tales. Ella es, por lo tanto, la que define adecuadamente para Hegel la relación de respectividad (Beziehung) entre Dios y mundo, entre lo infinito y lo finito.

Las determinaciones de la reflexión tienen un carácter polar. Cada polo no tiene sentido sin el otro, de modo análogo a como la operación + no tiene sentido sin la operación - (es impensable una estructura algebraica con la operación de suma y sin la operación de resta o viceversa). En cada uno de ellos aparece como lo más propio el otro. El otro es su otro. En esto consiste su independencia (Selbständigkeit). Como escribe Michael Theunissen,

La genuina independencia lógico-reflexiva reside en que lo uno que se halla frente a «su otro», es asimismo el todo que contiene a lo otro como su momento propio. ${ }^{7}$

La independencia se opone a la subsistencia (Beständigkeit). Aquella es una determinación de la reflexión; ésta del ser. Mientras que lo subsistente es previo e indiferente a la relación con su otro, lo independiente consiste justamente en contener en sí (en ser) esa relación con su otro. Dicho de otro modo: la relación propia del ser es la relación extrínseca o Verhältniss, mientras que la relación propia de la esencia es la relación de respectividad o Beziehung. Aquella conecta entes subsistentes; ésta configura un todo independiente. ${ }^{8}$ Dios, para la concepción teísta, es meramente subsistente, mientras que para Hegel ha de ser concebido como independiente.

En tanto que independientes, los polos o momentos de las determinaciones de la reflexión tienen cada uno en sí su opuesto. Así cada uno resulta ser la totalidad de la oposición. Pero puesto que cada lado es independiente, lo es respecto al otro, es decir, es el no-ser del otro y lo excluye. Es, dice Hegel, "la reflexión determinante en tanto que excluyente (als ausschliessende)" .9 Pero además como ese otro, en tanto que opuesto, es constitutivo de la determinación de la reflexión independien-

\footnotetext{
7 Theunissen, M.: Sein und Schein. Die kritische Funktion der hegelschen Logik, Frankfurt a.M., Suhrkamp, 1980, p. 28.

8 Véase sobre el contraste entre las determinaciones del ser y las determinaciones de la reflexión, $W d L$ (1832): $G W$. XXI, pp. 109-110 y $W d L$ (1813): $G W$. XI, pp. 259 y 266.

9 WdL (1813): GW. XI, p. 279.
} 
te a la que se opone (es decir, que ésta, en cuanto totalidad, lo incluye en sí), tal determinación "excluye de sí, en su propia independencia, su propia independencia". ${ }^{10}$ Dicho de otro modo: no es sino "el respecto a sí que se supera a sí" (aufhebende Beziehung auf sich). ${ }^{11}$ Como escribe André Léonard, cada término o lado de la oposición "no es él mismo más que no siendo él mismo y siendo él mismo, no es él mismo". ${ }^{12}$ Esta independencia que en sí misma se excluye a sí misma es la contradicción o Widerspruch.

Tal relación de reflexión excluyente es la que define para Hegel la relación entre Dios y lo finito: Dios no mantiene con lo finito una relación de mera alteridad, sino de reflexividad: interioriza a su opuesto de tal modo que, oponiéndose a él, se opone a sí mismo. Dios es así "la absoluta contradicción en sí misma". No sólo, como dice Hegel, por ser omnitudo realitatis, es decir, Inbegriff aller Realitäten, 13 es decir, por comprender en sí toda realidad y, por lo tanto, toda negación (pues toda realitas, en tanto que determinatio, es negatio), sino por definirse como lo opuesto a sí, es decir, por ser lo que no es.

La contradicción no es una determinación más de la reflexión sino el movimiento de desaparición de la reflexión. La contradicción se autoexcluye; más aún: ella es su autoexclusión. Esta autoexclusión es, a la vez, su hundimiento. La contradicción sucumbe a su propio movimiento y se abisma, se hunde. En la superficie, como único resto, por así decir, de su naufragio, flota, sostenida, fundada por lo sin fondo, la existencia (Existenz).

\section{Dios es abismo}

Hemos caracterizado al principio de estas líneas el ateísmo cristiano como aquel que relega a Dios a un tiempo anterior al tiempo, a un pasado intemporal. El pasado intemporal es el propio de la esencia. Esta es designada por Aristóteles con la expresión "tò ti ên eînai", quod quid erat esse, lo que era ser. La esencia es un antes más allá del tiempo; anterior al tiempo. Por eso dice Hegel que es pasado, pero pasado intemporal. ${ }^{14} \mathrm{El}$ tiempo de la esencia (Wesen) es el pasado (gewesen) porque la esencia es previa a todo ser. Donde ese "previa" no indica un prius temporal sino ontológico. La anterioridad esencial es la del supuesto en relación a lo puesto por él;15 la del fundamento respecto a lo por él fundado. ¿Cómo entiende Hegel esta

\footnotetext{
10 Ibid.

11 WdL (1813): GW. XI, p. 281.

12 Léonard, A.: Commentaire littéral de la Logique de Hegel, Paris/Louvaine, Vrin/Editions de L'institut Súpérieur de Philosophie, 1974, p.168.

13 WdL (1813), GW. XI, p. 289.

14 Ibid., p. 241.
} 
relación de fundamentación?¿Y en qué sentido puede y debe ser entendida como la expresión especulativa de la muerte de Dios?

La esencia para Hegel es un fundamento (Grund) que se abisma. Dicho de otro modo: es un abismo (Abgrund) que funda. ${ }^{16}$ La contradicción en la que desemboca la lógica de la reflexión es su hundimiento y, al mismo tiempo, "el fundamento de donde brota lo inmediato". ${ }^{17}$ Esa inmediatez fundamentada en el abismo es la existencia (Existenz). ${ }^{18}$ La existencia es la esencia misma pero en tanto que desaparecida. Como escriben Gwendoline Jarczyk y Pierre-Jean Labarriére, la razón (Grund) de la existencia está en la inexistencia de la esencia. ${ }^{19}$ La existencia no es Schein (apariencia) sino Erscheinung (aparición, fenómeno). ${ }^{20}$ Es decir, no se oculta tras ella algo esencial sino que, si expresa o manifiesta algo, ese algo se agota en tal manifestación. La esencia en Hegel no subsiste detrás de su Erscheinung, sino que es su Erscheinung. No hay nada tras esta. ${ }^{21}$

Dios, en tanto que esencia, es fundamento de la existencia. Esa existencia es, por lo tanto, su aparición, su revelación. 22 Pero en esa aparición, en ese revelarse como mundo, Dios se abisma.

Se dice -escribe Hegel en su Ciencia de la lógica- que la esencia de Dios es el abismo para la razón finita. En efecto es tal en la medida en que ella <es decir: la razón finita> renuncia allí a su finitud y hunde (versenkt) su movimiento mediador; pero este abismo (Abgrund), <que es $>$ el fundamento negativo, es al mismo tiempo el <fundamento $>$ positivo <es decir, que pone $>$ del brotar del ente, de la esencia inmediata en sí misma; la mediación es el momento esencial. La mediación por medio del fundamento se supera (hebt sich auf), pero no deja debajo al fundamento, de manera que lo que surge de él

15 Véase Zubiri, X.: Sobre la esencia, Madrid, Sociedad de Estudios y Publicaciones, 1962, pp. 46 y ss. Véase también: Marcuse, H.: Ontología de Hegel y teoría de la historicidad, Barcelona, Martínez Roca, 1970, pp.76-7.

16 Véase $W d L$ (1813), GW. XI, p. 28.

$17 W d L$ [1813], GW. XI, p. 326.

18 No me detengo aquí a analizar el despliegue categorial con el que se describe la dialéctica del fundamento en la Wesenslogik de 1813, dialéctica cuyo propósito y logro es alcanzar la unidad esencial, reflexiva, incondicionada, del ser determinado, inmediato, existente (la condición) de la cosa y su fundamento; unidad que no es finalmente sino la existencia de la cosa.

19 Véase Jarczyk, G. \& Labarriere, P.-J.: "Le statut logique de l'altérité chez Hegel”, Philosophie, 13, 1986, p.76, y Jarczyk, G.: "La logique de Hegel, principe du système", en Jarczyk, G. \& Labarriere, P.-J.: Hegeliana, Paris, PUF, 1986, p. 215.

20 Véase $W d L$ (1813): $G W$. XI, pp. 243 y 323.

${ }^{21}$ Enz. §131. Véase también Marcuse, H.: ob.cit., pp. 87-9.

22 En los apuntes de Hegel para las clases sobre teoría de la religión en el Gymnasium de Nuremberg (curso 1811-1813) se puede leer a propósito de Dios: "La esencia aparece (scheint) en sí misma; es fundamento de la existencia y aparece (erscheint); se revela como substancia absoluta*" (* al margen: "[lo] interior es lo mismo que lo exterior") (Religionslehre für die Mittel- und Oberklasse (1811-1813). Über den Begriff Gottes §[3]: W. IV, p. 280). 
sea un $<$ ser $>$ puesto, que tenga su esencia en otro lugar, es decir, en el fundamento, sino que este fundamento (Grund) es, como abismo (Abgrund), la mediación desaparecida; y viceversa, sólo la mediación desaparecida es al mismo tiempo el fundamento, y sólo por medio de esta negación <ella es> lo igual a sí mismo y lo inmediato. ${ }^{23}$

El fundamento (Grund) de lo inmediato es "mediación desaparecida", abismo (Abgrund). Este abismo es Dios.

La existencia, escribe Hegel, es la "absoluta enajenación (Entaüsserung)" de la esencia. ${ }^{24}$ En efecto, estamos ante el fin del periplo reflexivo iniciado con el ser y ante la vuelta a la inmediatez. 25 Se ha cerrado el círculo. Tras el hundimiento de la esencia sólo queda la superficie, los restos del naufragio. En este punto de inflexión de la lógica objetiva, justo en el centro de la razón hegeliana (la lógica), encontramos la enajenación, la locura.

Esta enajenación viene exigida por el segundo de los momentos del ciclo reflexivo: el de la diferencia (de la identidad y la diferencia). Este momento negativo, dialéctico, supera reflexivamente la reflexión. ${ }^{26}$ Dado que los dos momentos del movimiento reflexivo (la identidad y la diferencia) son idénticos (cada uno es la totalidad de la reflexión; es decir, es selbständig, independiente), su diferencia resulta ser la diferencia de la reflexión respecto a sí misma. La reflexión, por lo tanto, si es el retorno a sí, lo es como la negación, como el rechazo (Abstoß) de sí. "La esencia -escribe Hegel- retorna a sí como lo que niega", 27 es decir, retorna como "el no-ser [Nichtseyn] de la reflexión".28 Ese no-ser de la reflexión es la inmediatez, el ser entendido como pura exterioridad. 29

$23 W d L$ (1813): GW. XI, p. 326. Véanse también las pp. 321-322 y 317. Lo contenido entre paréntesis angulares es añadido mío.

24 WdL (1813): GW. XI, p. 326.

25 "La doctrina del ser contiene la primera proposición: El ser es la esencia. La segunda proposición: La esencia es el ser, constituye el contenido de la primera sección de la doctrina de la esencia" ( $W d L$ [1813]: GW. XI, p. 323. Véase también Lecrivain, A. et al.: Introduction à la lecture de la Science de la Logique de Hegel, Paris, Aubier-Montaigne, 1981-1987, t. II, p.102).

26 Sobre el segundo momento de lo lógico, el momento dialéctico o racional negativo véase: Enz. § 81: $W$. VIII, p. 172. Heinz Kimmerle ha visto en el momento hegeliano de la diferencia de la identidad y la diferencia la posibilidad de un pensamiento de la diferencia que permitiría ir más allá de la dialéctica, entendiendo este como la identidad de identidad y diferencia. Véase Kimmerle, H.: "Verschiedenheit und Gegensatz. Über das Verhältnis von Dialektik und Denken der Differenz", en Henrich D. (Hrsg.): Hegels Wissenschaft der Logik. Formation und Rekonstruktion, Stuttgart, KlettCotta, 1986, pp. 265-282.

27 WdL (1813): GW. XI, p. 292.

28 Ibid.

29 "Este ser puesto es, por ende, en primer lugar, el fundamento superado, la cosa como lo inmediato, lo no-reflexivo (Reflexionslose); el lado de las condiciones. Este $<$ lado $>$ es la totalidad de determinaciones de la cosa, $<$ es $>$ la cosa misma, pero extravertida (hinausgeworfen) en la exterioridad del ser; <es> el restaurado círculo del ser." (WdL [1813]: GW. XI, p. 319). 
La superación reflexiva de la reflexión hace que lo retornado no sea el ser del principio de la Lógica, lo inmediato indeterminado o simple, pues en tal caso nos moveríamos en un círculo, sino el ser esencial, lo inmediato puesto o mediado; es decir, la existencia. ${ }^{30}$ Ya no estamos, por lo tanto, en la mediación pura de la reflexión sino en la mediación real (reale Vermittlung) del fundamento, que "contiene la reflexión como reflexión superada". ${ }^{31}$ Esta estructura lógica metarreflexiva es la que ocasiona, en la espiral hegeliana, los sucesivos retornos a la inmediatez dentro de la lógica: el Dasein (en el ser), la Existenz (en la esencia) y el Objekt (en el concepto). 32 También la que hace posible la enajenación del lógos, que da lugar a la realidad tanto natural como espiritual. Es decir: la muerte de Dios.

\section{Dios muere, es decir: la lógica funda la realidad}

Que para Hegel Dios es la racionalidad misma, el lógos, es algo sabido. El contenido de la lógica, como leemos en la Introducción a la Ciencia de la lógica,

es la exposición de Dios tal como es en su esencia eterna antes de la creación de la naturaleza y de un espíritu finito. 33

En esta identidad de Dios y lógos ha visto Martin Heidegger la más conspicua manifestación de la ontoteología. En su curso sobre la Fenomenología del espiritu afirma que esa originaria unidad de teología especulativa y ontología "es lo que constituye el concepto auténtico de la lógica hegeliana". 34

\footnotetext{
${ }^{30}$ La reflexión hegeliana es y no es un retorno de lo mismo: es el retorno de lo mismo en tanto que otro; es el retorno de lo idéntico en tanto que diferente. Es el retorno del ser en tanto que existencia. Esta inmediatez retornada ya no es simple, sino reflejada. Esta diferencia o décalage entre ambos tipos de inmediatez es la que permite el progreso en la exposición; lo que D. Henrich llama Bedeutungsverschiebung (desplazamiento de significación) (Véase: "Hegels Logik der Reflexion", HegelStudien, Beiheft 18, especialmente pp. 248 y ss. y 266 y ss.), y hace que los círculos del sistema y el sistema mismo estén a la vez cerrados y abiertos (a modo de espiral logarítmica). Esta apertura es algo original y constitutivo del sistema hegeliano (Véase Hyppolite, J.: "Note sur la préface de la Phenomenologie de l'Esprit et le thème: l'absolu est sujet", en Hyppolite, J.: Figures de la pensée philosophique, Paris, PUF, 1991, t. I, pp. 336-337.) y diferencia su despliegue radicalmente de modelos como el de la epistrophé de Proclo, en la que no hay progreso alguno (Véase Gandillac, M. de: "Hegel et le néoplatonisme", en D'Hondt, J. [ed.]: Hegel et la pensée greque, Paris, PUF, 1974, p.128 y Vieillard-Baron, J.L.: Le temps. Platon, Hegel, Heidegger, Paris, Vrin, 1978, pp. 31-2).

31 WdL (1813): GW. XI, p. 292.

32 Véase $W d L$ (1813): $G W$. XI, p. 324.

33 WdL (1832): $G W$. XXI, p. 34.

34 Heidegger, M.: Hegels Phänomenologie des Geistes: Gesamtausgabe XXXII, Frankfurt a. M., V. Klostermann, 1988, p. 4.
} 
Si Dios es el lógos, la enajenación de la idea lógica puede ser entendida como la muerte de Dios. Y así, de hecho, la interpreta Hegel. En el manuscrito preparatorio para sus lecciones sobre filosofía de la religión podemos leer:

la suprema enajenación (Entaüsserung) de la idea divina -en cuanto enajenación DE ELLA Misma (...) se expresa $<$ así > : Dios ha muerto. 35

Esa enajenación de la idea divina es la gran articulación del sistema. El impulso por el que la lógica se transfigura en naturaleza sólo es comparable, escribe Ernst Bloch, al capricho soberano de un príncipe todopoderoso. ${ }^{36}$ Pero cabría pensar, sobre todo, en el estar fuera de sí, la enajenación, de un loco. El mismo Bloch habla del "loco estar-fuera-de-sí de la naturaleza hegeliana". 37

Puesto que la lógica es la esencia de la realidad,38 la razón de tal enajenación, de tal sinrazón hay que buscarla, a mi juicio, en el hundimiento de la esencia en y como existencia al que nos hemos referido más arriba. 39

El paso de la lógica a la naturaleza ha sido interpretado a veces como el trasunto especulativo del acto creador divino. Es el caso de Ludwig Feuerbach 40 o de Xavier Zubiri. ${ }^{41} \mathrm{Si}$ tal creación supone un agente que subsiste a la ejecución del acto creador, no hay propiamente creación en Hegel. 42 Dios (lo lógico) no subsis-

35 Vorlesungsmanuscripte I: GW. XVII, p. 265. La afirmación "Dios ha muerto" antes que de Nietzsche es de Hegel (El lugar clásico es el final de Glauben und Wissen: GW. IV, pp. 413-414), y fue anticipada por Pascal, como nos recuerda el propio Hegel: "La nature est telle, qu'elle marque partout un Dieu perdu, et dans l'homme, et hors de l'homme" (Penseés, fr. 436 ed. de M. Le Guern, fr. 441 ed. de L. Brunschvicg, fr. 471 ed. de L. Lafuma).

36 Bloch, E.: Subjekt-Objekt. Erläuterungen zu Hegel: Werkausgabe, Frankfurt a. M., Suhrkamp, 1985, t. VIII, p. 203.

37 Bloch, E., Ob. cit., p. 215.

38 La lógica es para Hegel el momento esencial, reflexivo del sistema: "el método <cuya exposición es la Lógica $>$ no es otra cosa sino la estructura ( $\mathrm{Bau}$ ) del todo, presentada en su esencialidad pura" (Phänomenologie des Geistes: GW. IX, p. 35); "la Idea lógica es ella misma <es decir, la Idea> en su pura esencia" ( $W d L$ [1816]: $G W$. XII, p. 237); "lo lógico es la eterna, simple esencia en sí misma" (Propädeutik I [1808 y ss.] § 10: W. IV, p. 11). Véase Jarczyk, G.: "La philosophie dans son concept est «La vérité en acte de savoir»", en Jarczyk, G. \& Labarriere, P.-J.: Hegeliana, ed. cit., pp. 285-293. 39 P.-J. Labarriére en su artículo "Die hegelsche Wissenschaft der Logik in und aus sich selbst: Strukturen und reflexive Bewegung" (Henrich, D. [Hrsg.]: ob. cit., pp. 102 y ss.) ha señalado acertadamente que la relación de respectividad que se da entre lo interior y lo exterior en cada una de las tres partes de la Lógica (ser/estar ahí, esencia/existencia, concepto/objetividad) es la misma que la que se da entre la interioridad del sistema (es decir, la Lógica) y la exterioridad del mismo (es decir, las ciencias reales: la Filosofía de la Naturaleza y la Filosofía del Espíritu).

40 Feuerbach, L.: Principios de la filosofía del futuro, Barcelona, Labor, 1976, pp. 37 y 61.

41 Zubiri, X.: Los problemas fundamentales de la metafísica occidental, Madrid, Alianza Ed., 1995, pp. 296-300.

42 Hegel critica expresamente tal concepción creacionista: “¿Cómo ha llegado Dios a crear el mundo? Se lo representa como si Dios fuera un sujeto, una realidad (Wirklichkeit), para sí, lejos del mundo; 
te al acto por el que crea la naturaleza, sino que es ese acto. Bernard Bourgeois lo ha expresado atinadamente:

Su $s e r<$ el de la idea lógica > -la identificación interna de su diferenciación, de su negación en ella misma- no es otra cosa que su acto -la diferenciación de ella misma respecto a ella misma, su negación de sí- de poner absolutamente a partir de ella misma, libremente, como otro que ella misma, como libre, lo que, en ella, es otro que ella misma en su verdad, a saber, la diferencia de su identidad y de su diferencia, brevemente, de crear la naturaleza. 43

Por lo tanto, el término "creación" (Schöpfung) en Hegel debe entenderse en el sentido de que Dios pone (setzt) lo otro de sí (el mundo) en virtud de la negativa relación de respectividad (die negative Beziehung) que mantiene con su propia esencia. 44 Es decir, si Dios "crea" el mundo lo hace en el mismo acto por el que se niega a sí mismo. Pone quitándose, hace deshaciéndose, crea destruyéndose. En lo creado Dios no subsiste como tal, sino que deja de ser Dios; se vacía de sí. Se trata, por lo tanto, de una genuina kénosis. ${ }^{45}$ El término "Entäusserung" (enajenación) del que se sirve Hegel, es la traducción luterana de la kénosis paulina:46 el "vaciamiento" de Dios en el Cristo, es decir, el devenir otro de Dios, su encarnación y muerte.

Lo real (es decir, la naturaleza y el espíritu) es la existencia de la lógica y, correlativamente, lo racional (es decir, la lógica) es la esencia (el fundamento abisal) de la naturaleza y el espíritu. La realidad existe como lo no lógico en virtud de la superación metarreflexiva de la lógica. La lógica en Hegel no es la realidad alienada e hipostasiada, como pensaron Feuerbach y Marx. No es un "más allá", no pertenece a la galería espectral de los trasmundos metafísicos, sino que es fundamento en el sentido que este término tiene en la Lógica de Hegel. Es decir, es lo que, hundiéndose, funda. Como acertadamente han escrito Gwendoline Jarczyk y Pierre-Jean Labarrière,

pero tal abstracta infinitud, tal universalidad, que estuviera fuera de lo particular, sería ella misma sólo un lado, por lo tanto ella misma un particular, algo finito..." (Enzyklopädie § 246, Zusatz: W. IX, p. 23). 43 Bourgeois, B.: "Le Dieu de Hegel: Concept et création", en Konninck Th. de \& Planty-Bonjour, G. (eds.): La question de Dieu selon Aristote et Hegel, Paris, PUF, 1991, p.315 (= Bourgeois, B.: Etudes hégeliénnes, Paris, P.U.F., 1992, pp. 343-4).

44 "La creación... es el respecto negativo (die negative Beziehung) de Dios a su esencia y de este modo pone (setzt) lo otro de sí" (Hegel, G.W.F.: Propädeutik. Religionslehre für die Mittel- und Oberklasse [1811-1813]. Über den Begriff Gottes § [10]: W. IV, p. 282).

45 Sobre la kénosis hegeliana véase: Malabou, C.: .L'avenir de Hegel. Plasticité, temporalité, dialectique, Paris, Vrin, 1996, pp. 129 y ss., y sobre todo, en el sentido de una lectura atea del cristianismo hegeliano: Altizer, Th.J.J.: The Gospel of Christian Atheism, Philadelphia, Westminster Press, 1966, Chap. 2, II.

46 Véase Flp. 2, 7. 
La 'reflexión' es precisamente esta identidad paradójica que hace que la lógica no ponga la realidad más que desapareciendo ella misma como lógica. 47

Esa desaparición es la muerte de Dios.

Tal muerte no es en Hegel algo trágico sino, por el contrario, una liberación (Befreiung). ${ }^{48}$ La liberación de Dios, entendiendo este genitivo tanto objetiva como subjetivamente, es decir: el acto por el que Dios se libera a sí mismo de sí mismo. No se trata, por lo tanto, como piensa Bernard Bourgeois de que "Dios se libera en él mismo de lo que él libera como mundo creado"49 sino más bien de que Dios se libera de sí mismo en lo que él libera como mundo creado. Dios no crea el mundo en el ejercicio de su libertad sino que, liberado de sí, es mundo. En virtud de esta negatividad suicida Dios no puede ser sino lo que no es. Este tener como momento más propio a lo otro de sí, y que por ello es, al mismo tiempo, un tenerse a sí mismo como lo otro de sí, es lo que en el sentido más propio entiende Hegel por libertad.50 Con razón ha caracterizado Ernst Bloch a la libertad hegeliana como lo profundo (Tiefe) del sí mismo, es decir, el hecho de que "ya no se encuentra afectado por lo objetivo como por algo extraño".51 Que la idea absoluta es libre quiere decir, por lo tanto, que ya no tiene a la realidad como lo otro ajeno e indiferente a sí, sino que es, por el contrario, su profundidad, su más propio sí mismo.

\section{Dios es la muerte de Dios}

Georg Büchner hace decir a Herault en su drama La muerte de Dantón: "para que Dios sea todo, tiene que ser también su propio contrario". 52 Hegel va más lejos. Según él Dios ha de ser su propio contrario para ser Dios. La muerte de Dios viene exigida por la esencia misma de Dios. ¿No podría entenderse esto como una suerte de argumento onto-a-teológico? Un argumento cuya lógica sería la de la enajenación de la esencia en la existencia a partir del fundamento. ${ }^{53}$ Dios existe, paradóji-

\footnotetext{
47 Jarczyk, G. \& Labarriere, P.-J.: Hegeliana, ed. cit., p. 25.

48 "La Idea se deja a sí misma libre (die Idee sich selbst frey entlässt) (...) por esta libertad la forma de su determineidad es así sencillamente libre (Um dieser Freyheit willen ist die Form ihrer Bestimmtheit eben so schlechthin frey)". WdL (1816): GW. XII, p. 253.

49 Bourgeois, B.: "Le Dieu de Hegel: concept et création": Etudes hégéliennes, ed. cit., pp. 332-3.

50 En el Zusatz al $\S 38$ de la Enzyclopädie se puede leer: "la libertad consiste justamente en que yo no tengo frente a mí ningún absolutamente otro, sino que <este $>$ depende de un contenido que soy yo mismo" (W. VIII, p. 111).

51 Ob. cit., p. 501.

52 Büchner, G.: Dantons Tod III,1: Sämtliche Werke (ed. H. Poschmann), Frankfurt a. M., Deutscher Klassiker Verlag, 1992, t. I, p. 58.

53 Véase $W d L$ (1813): GW. XI, pp. 324-5.
} 
camente, dejando de ser Dios; muriendo en la cruz del presente. Este es el genuino sentido del Cristo hegeliano. ${ }^{54}$ Lo absoluto no es para Hegel algo ajeno a los procesos de la naturaleza y al acontecer de la historia, sino que se agota en esa realidad procesual y aconteciente. No es, en definitiva, sino tiempo natural e histórico. Como escribe Jean Beaufret, lo absoluto en Hegel

no es como un monte solitario que se contentara con ser cima. Nada le es más propio que rebajarse por debajo de sí mismo, pues solamente en esto culmina. .55

El idealismo absoluto hegeliano, en la medida en que concibe una razón que funda la existencia $y$, en virtud de tal fundamentación, se identifica, sin resto, con lo que funda, desemboca en un realismo no menos absoluto. 56

Cabría pensar, no obstante, que el sistema es un círculo, y que, por consiguiente, el camino de ida de la razón a la realidad exige o reclama el de vuelta de la realidad a la razón. En términos teológicos: Viernes Santo y Domingo de Resurrección. Ambos constituirían los dos momentos del ciclo sistemático: Por un lado, el abismamiento y pérdida de la razón en y como tiempo y por otro, la redención de la realidad al concebirla como una estructura totalizante, necesaria, eterna. Muerte y resurrección de Dios. 57

54 Véanse los $\S \S 567-9$ de la Enzyklopädie y el Vorlesungsmanuskript de Filosofía de la Religión ( $G W$. XVII, p. 251 y ss.). Especialmente, sobre el sentido especulativo de la muerte de Cristo véase el susodicho Vorlesungsmanuskript (ibid.p. 264 y ss.). Véase también Bourgeois, B., "Le Christ hégélien" en Bourgeois, B.: Etudes hégéliennes. Raison et décision, Paris, PUF, 1992, pp. 321-2.

55 Beaufret, J., "Hegel et la proposition spéculative", en Beaufret, J.: Dialogue avec Heidegger II, Minuit, Paris, 1973, p. 125. Véase también la p.141.

56 Esto es lo que ha llevado a Robert Lamblin a interpretar el idealismo hegeliano como ateísmo. Véase Lamblin, R.: Une interpretation athée de l'idealisme hegelien. Raison absolue théologique ou raison absolue philosophique finie, Paris, 1'Harmattan, 1998. La identidad de idea y realidad en Hegel fue advertida con perspicacia por Pierre Drieu la Rochelle en una nota de su diario de 1944-5: "Su idealismo absoluto [e.d., el de Hegel] es un realismo absoluto" (Drieu La Rochelle, P.: Relato secreto, Madrid, Alianza Ed., 1978, p.70). Encontramos una idea similar en Th.W. Adorno: "Hegel se acerca tanto más al materialismo social cuanto más lejos lleva el idealismo, incluso el gnoseológico" (Adorno, Th.W., Drei Studien zu Hegel: Adorno, Th.W., Gesammelte Schriften V, Frankfurt a. M., Suhrkamp, 1997, p. 307. Véase también Van Der Meulen, J.: "Begriff und Realität", en Gadamer H.G. (Hrsg.): ob. cit., p. 132 y Labarriere, P.-J. "L'idéalisme absolu de Hegel: de la logique comme métaphysique", en Jarczyk, G. \& Labarriere, P.-J.: ob. cit., p.203).

57 Esta es la postura defendida, por ejemplo, por Hans Küng, quien polemiza con los teólogos de la muerte de Dios (Thomas J.J. Altizer, W. Hamilton, G. Vahanian, etc.), los cuales se inspiran justamente en Hegel. Según Küng "Hegel no predica un «evangelio del ateísmo cristiano», sino más bien, podría decirse, una «supresión cristiana del ateísmo», no predica «un ateísta creer en Dios», sino «una fe post-ateísta en Dios». Precisamente porque se trata de la muerte de Dios, del viernes santo se sigue la resurrección. Precisamente porque se trata del viernes santo de Dios mismo, el dolor infinito ha de ser entendido «como momento y sólo como momento de la idea suprema» (I, 346). Por tratarse del absoluto mismo, él «puede y tiene que resucitar» del abismo de la nada, superándose en cierto modo 
El círculo hegeliano, sin embargo, no se cierra sobre sí mismo. El punto de llegada no es el mismo que el de partida. ${ }^{58}$ El espíritu no es una vuelta al lógos en su esencialidad pura, sino que es el lógos encarnado (humanado, diría San Juan de la Cruz). Esa encarnación conlleva la finitud y la muerte. El espíritu no implica, por lo tanto, en rigor, la resurrección del hombre sino la muerte de Dios. La asunción radical de esa muerte (que es nuestra muerte) es justamente lo que hace que el espíritu conquiste su verdad, es decir, lo que nos hace cabalmente hombres. Como ha escrito Hegel en el Prólogo a su Fenomenología del Espíritu:

La vida del espíritu no es la vida que se espanta ante la muerte y se salvaguarda pura de la desolación, sino la que sabe soportarla y se mantiene en ella. El espíritu sólo conquista su verdad cuando se encuentra a sí mismo en el absoluto desgarramiento. 59

Por lo tanto, este mundo no remite, según Hegel, a un trasmundo que rescate y custodie su sentido. Dios ha muerto ya desde siempre, y la orfandad originaria de sentido que eso implica es el único sentido de lo que hay. No hay, por lo tanto, más sentido que la ausencia de sentido, no hay más Dios que la muerte de Dios, no hay más razón que la sinrazón de lo que hay. El Lógos no salva al sentido de su naufragio en el tiempo, sino que es, justamente, ese naufragio. La filosofía de Hegel no ha programado un final de la historia en el que se resolverán las disonancias. La razón absoluta hegeliana ha hecho suya la tarea hacer de este aquí y ahora desamparado y mortal (el hiersein de la novena elegía de Rilke) lo único absoluto. Vivir plenamente conscientes de que no hay ninguna trascendencia redentora es la única redención posible; la única, al menos, que hace justicia a lo humano del hombre.

\section{Referencias bibliográficas}

Adorno, Th. W.: Drei Studien zu Hegel, en Adorno, Th. W.: Gesammelte Schriften V, Frankfurt a. M., Suhrkamp, 1997.

Altizer, Th. J.J.: The Gospel of Christian Atheism, Philadelphia, Westminster Press, 1966.

a sí mismo, como «la suprema totalidad en toda su seriedad y desde su más profundo fundamento, abarcándolo a la vez todo y con la más gozosa libertad de su forma» (I, 346). Así queda superada y transformada la privación atea de Dios que sufre el mundo: desde el abandono de Dios que experimente Jesús, o que experimente Dios mismo" (Küng, H.: La encarnación de Dios. Introducción al pensamiento de Hegel como prolegómenos para una cristología futura, Barcelona, Herder, 1974, p. 236. Las citas de Küng están tomadas de Hegel, G.W.F.: Kritische Gesamtausgabe, ed. de LassonHoffmeister, t.I [Erste Druckschriften]).

58 Véase supra nota 30.

$59 G W$. IX, p. 27. Véase sobre este texto Bataille, G.: "Hegel, la mort et le sacrifice" en Bataille, G.: Oeuvres complètes, Paris, Gallimard, 1988, t. XII. 
Bataille, G.: "Hegel, la mort et le sacrifice", en Bataille, G.: Oeuvres complètes t. XII, Paris, Gallimard, 1988.

BeAufret, J.: "Hegel et la proposition spéculative", en Beaufret, J.: Dialogue avec Heidegger II, Paris, Minuit, 1973.

BLoch, E.: El ateísmo en el cristianismo, Madrid, Taurus, 1983.

BLoch, E.: Subjekt-Objekt. Erläuterungen zu Hegel, en Bloch, E.: Werkausgabe, Frankfurt am M.,Suhrkamp, 1985.

Bourgeors, B.: "Le Dieu de Hegel: Concept et création", en Konninck, Th. de \& Planty-Bonjour, G. (eds.): La question de Dieu selon Aristote et Hegel, Paris, PUF, 1991.

Bourgeois, B.: "Le Christ hégélien", en Bourgeois, B.: Etudes hégéliennes. Raison et décision, Paris, PUF, 1992.

Boutang, P. y Steiner, G.: Diálogos. Sobre el mito de Antígona y el sacrificio de Abraham, Barcelona, Destino, 1994.

Büchner, G.: Sämtliche Werke (ed. H. Poschmann), Frankfurt a. M., Deutscher Klassiker Verlag, 1992.

Drieu La Rochelle, P.: Relato secreto, Madrid, Alianza Ed., 1978.

Feuerbach, L.: Principios de la filosofía del futuro, Barcelona, Labor, 1976.

Gandillac, M. de: "Hegel et le néoplatonisme", en D’Hondt, J. [ed.]: Hegel et la pensée greque, Paris, PUF, 1974.

HegEL, G.W.F.: Gesammelte Werke, ed. crítica de la Rheinisch-Westfälischen Akademie der Wissenschaften en colaboración con la Deutschen Forschungsgemeinschaft, Hamburgo, Felix Meiner, 1968 ss.

Hegel, G.W.F.: Werke, Frankfurt a. M., Suhrkamp, 1986.

Heidegger, M.: Hegels Phänomenologie des Geistes, en Heidegger, M.: Gesamtausgabe XXXII, Frankfurt a. M., V. Klostermann, 1988.

Henrich, D.: "Hegels Logik der Reflexion", en Henrich, D. (ed.): Die Wissenschaft der Logik und die Logik der Reflexion (Hegel-Tage Chantilly, 1971), Bonn, Bouvier Verlag Herbert Grundmannn, 1978 (=Hegel-Studien, Beiheft 18).

Hyppolite, J.: "Note sur la préface de la Phenomenologie de l'Esprit et le thème: l'absolu est sujet", en Hyppolite, J.: Figures de la pensée philosophique, Paris, PUF, 1991.

JarczyK, G. \& LABARriere, P.-J.: Hegeliana, Paris, PUF, 1986.

JARCZYK, G. \& LABARRIERE, P.-J.: "Le statut logique de l'altérité chez Hegel", Philosophie, 13, 1986.

KAFKA, F.: Hochzeitsvorbereitungen auf dem Lande und andere Prosa aus dem Nachlass (ed. M. Brod), Frankfurt a. M., Fischer Taschenbuch Verlag, 1998.

KIMMERLE, H.: "Verschiedenheit und Gegensatz. Über das Verhältnis von Dialektik und Denken der Differenz", en D. Henrich (ed.): Hegels Wissenschaft der Logik. Formation und Rekonstruktion, Stuttgart, Klett-Cotta, 1986. 
KüNG, H.: La encarnación de Dios. Introducción al pensamiento de Hegel como prolegómenos para una cristología futura, Barcelona, Herder, 1974.

LABARRIĖRE, P.-J.: "Die hegelsche Wissenschaft der Logik in und aus sich selbst: Strukturen und reflexive Bewegung" en Henrich, D. (ed.): Hegels Wissenschaft der Logik. Formation und Rekonstruktion, Stuttgart, Klett-Cotta, 1986.

LAMBLIN, R.: Une interpretation athée de l'idealisme hegelien. Raison absolue théologique ou raison absolue philosophique finie, Paris, l'Harmattan, 1998.

LeCRIVAIN, A. et al.: Introduction à la lecture de la Science de la Logique de Hegel, Paris, Aubier-Montaigne, 1981-1987.

LÉONARD, A.: Commentaire littéral de la Logique de Hegel, Paris/Louvaine, Vrin/Editions de L'institut Súpérieur de Philosophie, 1974.

LöwıTH, K.: "Hegels Aufhebung der christlichen Religion", en Gadamer, H.-G. (ed.): Heidelberger Hegel-Tage 1962, Bonn, Bouvier Verlag Herbert Grundmann, 1984 (= Hegel-Studien, Beiheft 1).

Malabou, C.: L'avenir de Hegel. Plasticité, temporalité, dialectique, Paris, Vrin, 1996.

Marcuse, H.: Ontología de Hegel y teoría de la historicidad, Barcelona, Martínez Roca, 1970.

Meulen, J. van der: "Begriff und Realität", en Gadamer, H.-G. (ed.): Heidelberger Hegel-Tage 1962, Bonn, Bouvier Verlag Herbert Grundmann, 1984 (= HegelStudien, Beiheft 1).

Theunissen, M.: Sein und Schein. Die kritische Funktion der hegelschen Logik, Frankfurt a.M., Suhrkamp, 1980.

Vieillard-Baron, J.L.: Le temps. Platon, Hegel, Heidegger, Paris, Vrin, 1978.

ZuBiRI, X.: Sobre la esencia, Madrid, Sociedad de Estudios y Publicaciones, 1962.

ZuBIRI, X.: Los problemas fundamentales de la metafisica occidental, Madrid, Alianza Ed., 1995

Jesús Ezquerra Gómez

Departamento de Filosofía

Facultad de Filosofía y Letras

Universidad de Zaragoza

jesusezq@unizar.es 